\title{
Optimal control of an HIV infection model with logistic growth, celluar and homural immune response, cure rate and cell-to-cell spread
}

\author{
Najmeh Akbari ${ }^{*}$ (ID and Rasoul Asheghi
}

"Correspondence:

najmeh.akbari@math.iut.ac.ir 'Department of Mathematical Sciences, Isfahan University of Technology, Isfahan, Iran

\section{Springer}

\begin{abstract}
In this paper, we propose an optimal control problem for an HIV infection model with cellular and humoral immune responses, logistic growth of uninfected cells, cell-to-cell spread, saturated infection, and cure rate. The model describes the interaction between uninfected cells, infected cells, free viruses, and cellular and humoral immune responses. We use two control functions in our model to show the effectiveness of drug therapy on inhibiting virus production and preventing new infections. We apply Pontryagin maximum principle to study these two control functions. Next, we simulate the role of optimal therapy in the control of the infection by numerical simulations and AMPL software.
\end{abstract}

Keywords: Logistic growth; Cure rate; Cellular immune response; Humoral immune response; Cell-to-Cell spread; Article; Optimal control

\section{Introduction}

Acquired immune deficiency syndrome (in short, AIDS) is caused by a type of lentivirus called human immunodeficiency virus (HIV). The life cycle of HIV is not yet completely understood. Studies show that the spread of the virus leads to the decreasing of immune cells and the creating of opportunistic infections. When the number of immune cells reaches less than 200, AIDS happens. The normal time from the entry of the virus to a cell to the occurring of AIDS is between 7 and 10 years, varying from one person to another person [1-4]. Many countries have been affected by the HIV-1 virus for many years. The virus is spreading rapidly in some areas. Many researchers [5-17] have been developed mathematical models to understand the dynamics of HIV. Due to the rapid spread of HIV-1 in some areas, many countries have been found some ways for fighting HIV-1 $[18,19]$. One way is to use drugs that help the immune system to prevent the spread of HIV infection. These drugs are called antiretroviral drugs. Antiretroviral therapy, used to treat HIV in most countries, can restore the immune system and prevent opportunistic infections. These treatments reduce the production of new infections and the rate of HIV transmission. These methods increase the life expectancy of HIV-infected patients.

(c) The Author(s) 2022. This article is licensed under a Creative Commons Attribution 4.0 International License, which permits use, sharing, adaptation, distribution and reproduction in any medium or format, as long as you give appropriate credit to the original author(s) and the source, provide a link to the Creative Commons licence, and indicate if changes were made. The images or other third party material in this article are included in the article's Creative Commons licence, unless indicated otherwise in a credit line to the material. If material is not included in the article's Creative Commons licence and your intended use is not permitted by statutory regulation or exceeds the permitted use, you will need to obtain permission directly from the copyright holder. To view a copy of this licence, visit http://creativecommons.org/licenses/by/4.0/. 
One of these drugs is the reverse transcriptase inhibitor (RTI), which prevents the conversion of viral RNA to DNA and produces infected mature cells. Protease inhibitor (PI) prevents virus production from infected cells $[20,21]$. Since these treatments are singly detrimental to the patient, an optimal therapy for the treatment of HIV infection using a combination of multiple appropriate treatment strategies is needed. Due to the lack of understanding of the mechanisms among host cells, HIV infection, and the happening of AIDS, many questions have been raised: What is the best combination? When is the appropriate time to start the treatment? How this treatment should be done? Some HIV mathematical models [22-29] play a significant role in understanding the dynamics of viral transmission, drug therapy, and HIV-1 improvement. Optimal control theory [30] is a branch of mathematical science that helps us to find optimal ways to control infectious diseases. One of the optimal ways is to use the best drug dosage to treat and control the infection.

In this paper, we propose a new mathematical model of HIV, which is an extension of the model developed in $[16,17]$. In the presented model, we use the logistic function to describe the rate of mitotic proliferation of healthy cells, the saturation function for virusto-cell transmission, cell-to-cell transmission, and cellular and humoral immune. We also consider the cure rate (namely, the conversion rate of infected cells to healthy cells) by gene therapy or loss of all cccDNA from their nucleus [31].

This paper is organized as follows: In Sect. 2, we formulate our new model with five state variables and two control functions. In Sect. 3, by introducing two drug controllers, we state the necessary conditions for the existence of optimal control. In Sect. 4, we illustrate the numerical simulation of the model. In Sect. 5, we conclude.

\section{Model formulation}

The population of $C D_{4}^{+}$T-cells is stimulated and divided by the antigen, and this proliferation stops when it reaches its maximum value. Hence, we can use the logistic function to describe this process $[32,33]$. To construct a more realistic model, we use the saturation function instead of the bilinear infection rate [16, 34]. Besides the virus-to-cell transmission, we will use the rate of cell-to-cell transmission [9]. Both cellular and humoral immune systems are included in our model for investigating the effectiveness of the Foutz vaccine design [14]. The principle of the Kaminsky gene therapy states that the cure rate can be used to avert the infected cells to uninfected cells [31]. Due to the effect of antiviral drugs on HIV control and personal health, we consider two control functions to study their effect [15]. In view of the above assumptions, we provide a new model with five state variables. The state variables of this model are denoted by $x, y, v, z$, wh which are respectively: Population of uninfected $C D_{4}^{+}$T-cells, Population of infected $C D_{4}^{+}$T-cells, Population of infectious HIV virions, Population of T-cells, Population of B-cells. Moreover, two control functions denoted by $u_{1}(t)$ and $u_{2}(t)$, are introduced as reverse transcriptase inhibitor (RTI) and protease inhibitor (PI), respectively. RTI prevents the transcription process in HIV-infected cells and PI blocks the protease enzyme and prevents the production of infection and adult viruses. Our proposed model is given below.

$$
\begin{aligned}
& \frac{d x}{d t}=r x\left(1-\frac{x+y}{m}\right)-\frac{\left(1-u_{1}(t)\right) \beta_{1} v x}{1+\alpha v}-\beta_{2} x y+\rho y-d x, \\
& \frac{d y}{d t}=\frac{\left(1-u_{1}(t)\right) \beta_{1} v x}{1+\alpha v}+\beta_{2} x y-(\delta+\rho) y-\rho_{1} y z,
\end{aligned}
$$


Table 1 Used parameters in HIV mathematical model

\begin{tabular}{ll}
\hline Parameters & Description \\
\hline$r$ & The rate at which the $C D_{4}^{+}$T-cells are reproduced. \\
$m$ & Maximum value of $C D_{4}^{+}$T-cells in the absence of the virus. \\
$\beta_{1}$ & The rate at which the virus infects the $C D_{4}^{+}$T-cells. \\
$\beta_{2}$ & The rate at which the $C D_{4}^{+}$T-cells are infected by the infected cells. \\
$\alpha$ & The rate at which the viruses are saturated. \\
$\rho$ & The cure rate of the infected $C D_{4}^{+}$T-cells that reverted to the uninfected T-cells. \\
$d$ & The death rate of the $C D_{4}^{+}$T-cells. \\
$\delta$ & The death rate of the infected $C D_{4}^{+}$T-cells. \\
$\rho_{1}$ & The rate at which the T-cells kill the infected $C D_{4}^{+}$T-cells. \\
$n$ & Number of viruses produced by the infected $C D_{4}^{+}$T-cells. \\
$\mu$ & The death rate of the viruses. \\
$\rho_{2}$ & The rate at which the B-cells kill the viruses. \\
$c_{1}$ & The rate at which the presence of the infected T-cells activates the T-cells. \\
$b_{1}$ & The death rate of the T-cells. \\
$c_{2}$ & The rate at which the presence of the virus activates the B-cells. \\
$b_{2}$ & The death rate of the B-cells. \\
\hline
\end{tabular}

$$
\begin{aligned}
& \frac{d v}{d t}=\left(1-u_{2}(t)\right) n \delta y-\mu v-\rho_{2} v w, \\
& \frac{d z}{d t}=c_{1} y z-b_{1} z, \\
& \frac{d w}{d t}=c_{2} v w-b_{2} w .
\end{aligned}
$$

All parameters presented in model (2.1) are positive and independent of time. They are defined in Table 1 . The $u_{1}$ controller shows the impact of reverse transcriptase inhibitors, and the $u_{2}$ controller indicates the effect of protease inhibitor. These two controllers are time-dependent and limited to 0 and 1 . The case $u_{1}=u_{2}=0$ denotes $0 \%$ efficacy of the reverse transcriptase and protease inhibitors, while the case $u_{1}=u_{2}=1$ indicates $100 \%$ efficacy of the reverse transcriptase and protease inhibitors. To begin, we assume that $\Phi(t)=(x(t), y(t), v(t), z(t), w(t))$ is an integral curve of the system (2.1) parameterized by the time variable $t$. Now, we define an objective function as follows:

$$
J\left(u_{1}(t), u_{2}(t)\right)=\int_{0}^{t_{f}}\left(x(t)+z(t)+w(t)-v(t)-\frac{E_{1}}{2} u_{1}^{2}(t)-\frac{E_{2}}{2} u_{2}^{2}(t)\right) d t
$$

In the above definition, the parameter $t_{f}$ denotes the terminal time of the treatment, and the parameters $E_{1}$ and $E_{2}$ represent non-negative weight factors of the treatment for inhibiting the reverse transcriptase and protease enzymes. The quadratic expressions of $u_{1}$ and $u_{2}$ represent non-linear costs of the treatment, as pointed in [35]. We assume that $u_{1}$ and $u_{2}$ are piecewise continuous and Lebesgue-integrable.

Remark 2.1 Given a continuous function $g(t)$ on the time interval $[a, b]$. Its average on this interval is given by

$$
\bar{g}=\frac{1}{b-a} \int_{a}^{b} g(t) d t
$$

Therefore, the integral defined in (2.2) denotes the average of the function $g(t)=t_{f}\left(g_{1}(t)-\right.$ $\left.g_{2}(t)\right)$ on the interval $\left[0, t_{f}\right]$, where $g_{1}(t)=x(t)+z(t)+w(t)$ and $g_{2}(t)=v(t)+\frac{E_{1}}{2} u_{1}^{2}(t)+\frac{E_{2}}{2} u_{2}^{2}(t)$. 
We note that $g_{1}(t)$ is the summation of the uninfected, cellular, and humoral immune cells, while $g_{2}(t)$ is the summation of the population of viruses and the dosage of the drugs at time $t$. Hence, the best strategy for treating HIV infection is to maximize the objective function (2.2).

We aim to find the optimal controls $u_{1}^{*}$ and $u_{2}^{*}$ such that

$$
J\left(u_{1}^{*}(t), u_{2}^{*}(t)\right)=\max \left\{J\left(u_{1}(t), u_{2}(t)\right):\left(u_{1}(t), u_{2}(t)\right) \in U\right\},
$$

where $U$ is a measurable control set described by

$$
U=\left\{\left(u_{1}(t), u_{2}(t)\right): u_{1}, u_{2} \text { are measurable on }\left[0, t_{f}\right] \text {, and } 0 \leq u_{1}, u_{2} \leq 1\right\} .
$$

\section{The necessary conditions for the existence of optimal control}

In this section, by using the Pontryagin maximum principle [30], we obtain the necessary conditions for the existence of optimal control for system (2.1). The Pontryagin maximum principle states: if $u^{*}(t)=\left(u_{1}^{*}, u_{2}^{*}\right) \in U$ is an optimal control for (2.2) with a fixed terminal time $t_{f}$, then there exists an adjoint vector $\lambda(t)$ with five adjoint variables $\lambda_{1}, \lambda_{2}, \lambda_{3}, \lambda_{4}, \lambda_{5}$, which is defined as

$$
\begin{aligned}
& \lambda:\left[0, t_{f}\right] \rightarrow \mathbb{R}^{5}, \\
& \lambda(t)=\left(\lambda_{1}(t), \lambda_{2}(t), \lambda_{3}(t), \lambda_{4}(t), \lambda_{5}(t)\right),
\end{aligned}
$$

such that for all $t \in\left[0, t_{f}\right]$, the following conditions are satisfied.

1. The state variables are obtained from the below equations:

$$
\begin{array}{ll}
\frac{d x}{d t}=\frac{\partial H\left(t, u_{1}^{*}, u_{2}^{*}, \lambda(t)\right)}{\partial \lambda_{1}}, & \frac{d y}{d t}=\frac{\partial H\left(t, u_{1}^{*}, u_{2}^{*}, \lambda(t)\right)}{\partial \lambda_{2}}, \\
\frac{d v}{d t}=\frac{\partial H\left(t, u_{1}^{*}, u_{2}^{*}, \lambda(t)\right)}{\partial \lambda_{3}}, & \frac{d z}{d t}=\frac{\partial H\left(t, u_{1}^{*}, u_{2}^{*}, \lambda(t)\right)}{\partial \lambda_{4}}, \\
\frac{d w}{d t}=\frac{\partial H\left(t, u_{1}^{*}, u_{2}^{*}, \lambda(t)\right)}{\partial \lambda_{5}} . &
\end{array}
$$

2. The optimal control values $u_{1}^{*}$ and $u_{2}^{*}$ can be obtained from the optimality conditions:

$$
\frac{\partial H\left(t, u_{1}^{*}, u_{2}^{*}, \lambda(t)\right)}{\partial u_{1}}=0, \quad \frac{\partial H\left(t, u_{1}^{*}, u_{2}^{*}, \lambda(t)\right)}{\partial u_{2}}=0 .
$$

3. The adjoint equations can be solved from

$$
\begin{array}{rlrl}
\frac{d \lambda_{1}}{d t} & =-\frac{\partial H\left(t, u_{1}^{*}, u_{2}^{*}, \lambda(t)\right)}{\partial x}, & & \frac{d \lambda_{2}}{d t}=-\frac{\partial H\left(t, u_{1}^{*}, u_{2}^{*}, \lambda(t)\right)}{\partial y}, \\
\frac{d \lambda_{3}}{d t}=-\frac{\partial H\left(t, u_{1}^{*}, u_{2}^{*}, \lambda(t)\right)}{\partial v}, & \frac{d \lambda_{4}}{d t}=-\frac{\partial H\left(t, u_{1}^{*}, u_{2}^{*}, \lambda(t)\right)}{\partial z}, \\
\frac{d \lambda_{5}}{d t}=-\frac{\partial H\left(t, u_{1}^{*}, u_{2}^{*}, \lambda(t)\right)}{\partial w} . &
\end{array}
$$


According to the Pontryagin maximum principle, the Hamiltonian function $H$ for our problem is defined as

$$
\begin{aligned}
H\left(x, y, v, z, w, \lambda_{1}, \lambda_{2}, \lambda_{3}, \lambda_{4}, \lambda_{5}, u_{1}, u_{2}\right) \\
=x+z+w-v-\frac{E_{1}}{2} u_{1}^{2}-\frac{E_{2}}{2} u_{2}^{2} \\
\quad+\lambda_{1}\left(r x\left(1-\frac{x+y}{m}\right)-\frac{\left(1-u_{1}\right) \beta_{1} v x}{1+\alpha v}-\beta_{2} x y+\rho y-d x\right) \\
\quad+\lambda_{2}\left(\frac{\left(1-u_{1}\right) \beta_{1} v x}{1+\alpha v}+\beta_{2} x y+(\delta+\rho) y-\rho_{1} y z\right) \\
\quad+\lambda_{3}\left(\left(1-u_{2}\right) n \delta y-\mu v-\rho_{2} v w\right)+\lambda_{4} z\left(c_{1} y-b_{1}\right)+\lambda_{5} w\left(c_{2} v-b_{2}\right) .
\end{aligned}
$$

The adjoint variables satisfy

$$
\begin{aligned}
\dot{\lambda}_{1}= & -\frac{\partial H}{\partial x}=-1-\lambda_{1}\left(r-d-\frac{r y}{m}-\frac{2 r x}{m}-\frac{\left(1-u_{1}\right) \beta_{1} v}{1+\alpha v}-\beta_{2} y\right) \\
& -\lambda_{2}\left(\frac{\left(1-u_{1}\right) \beta_{1} v}{1+\alpha v}+\beta_{2} y\right), \\
\dot{\lambda}_{2}= & -\frac{\partial H}{\partial y}=-\lambda_{1}\left(\rho-\frac{r x}{m}-\beta_{2} x\right)-\lambda_{2}\left(\beta_{2} x-\delta-\rho-\rho_{1} z\right)-\lambda_{3}\left(1-u_{2}\right) n \delta-\lambda_{4} c_{1} z, \\
\dot{\lambda}_{3}= & -\frac{\partial H}{\partial v}=1+\lambda_{1} \frac{\left(1-u_{1}\right) \beta_{1} x}{(1+\alpha v)^{2}}-\lambda_{2} \frac{\left(1-u_{1}\right) \beta_{1} x}{(1+\alpha v)^{2}}+\lambda_{3}\left(\mu+\rho_{2} \omega\right)-\lambda_{5}\left(c_{2} v-b_{2}\right), \\
\dot{\lambda}_{4}= & -\frac{\partial H}{\partial z}=-1+\lambda_{2} \rho_{1} y+\lambda_{4}\left(b_{1}-c_{1} y\right), \\
\dot{\lambda}_{5}= & -\frac{\partial H}{\partial w}=-1+\lambda_{3} \rho_{2} v+\lambda_{5}\left(b_{2}-c_{2} v\right) .
\end{aligned}
$$

Since $\lambda_{i}\left(t_{f}\right)=0$ for $i=1,2,3,4,5$, they are called the transversality conditions.

Theorem 3.1 Consider the objective function $J\left(u_{1}(t), u_{2}(t)\right)$ defined in (2.2). Then, there exists an optimal control $\left(u_{1}^{*}(t), u_{2}^{*}(t)\right) \in U$ such that

$$
J\left(u_{1}^{*}(t), u_{2}^{*}(t)\right)=\max _{u_{1}, u_{2} \in U} J\left(u_{1}(t), u_{2}(t)\right) .
$$

Moreover, the optimal controls $u_{1}^{*}$ and $u_{2}^{*}$ maximizing the objective function (2.2) are given by

$$
\begin{aligned}
& u_{1}^{*}(t)=\min \left(\max \left(0, \frac{\beta_{1}\left(\lambda_{1}-\lambda_{2}\right) x v}{E_{1}(1+\alpha v)}\right), 1\right), \\
& u_{2}^{*}(t)=\min \left(\max \left(0,-\frac{n \delta y \lambda_{3}}{E_{2}}\right), 1\right),
\end{aligned}
$$

where $x=x^{*}(t), y=y^{*}(t)$, and $v=v^{*}(t)$ are the solutions of system (2.1).

Proof From the results obtained by Fleming and Rishel [36], we can show the existence of the solution by using the following facts. 
(i) The set of all controls contained in $U$ are non-negative and Lebesgue-integrable on $\left[0, t_{f}\right]$.

(ii) The right-hand side of the system (2.1) is bounded by a linear function of the state and control variables, and thus the solutions exist.

(iii) The set $U$ is convex and closed.

(iv) The integrand of the objective function, $x(t)+z(t)+w(t)-v(t)-\frac{E_{1}}{2} u_{1}^{2}-\frac{E_{2}}{2} u_{2}^{2}$, is concave on $U$. To prove this, we use the fact that a multi-variable function as $f\left(x_{1}, \ldots, x_{n}\right)$ is concave if and only if the Hessian matrix

$$
H(x)=\left[\frac{\partial^{2} f(x)}{\partial x_{i} \partial x_{j}}\right]
$$

is semi-negative definite. We set $\mathcal{F}\left(u_{1}, u_{2}\right)=x+z+w-v-\frac{E_{1}}{2} u_{1}^{2}-\frac{E_{2}}{2} u_{2}^{2}$, which admits the Hessian matrix

$$
\mathcal{H}(u)=\left[\begin{array}{cc}
\frac{\partial^{2} \mathcal{F}}{\partial u_{1}^{2}} & \frac{\partial^{2} \mathcal{F}}{\partial u_{1} \partial u_{2}} \\
\frac{\partial^{2} \mathcal{F}}{\partial u_{2} \partial u_{1}} & \frac{\partial^{2} \mathcal{F}}{\partial u_{2}^{2}}
\end{array}\right]=\left[\begin{array}{cc}
-E_{1} & 0 \\
0 & -E_{2}
\end{array}\right] .
$$

Since $E_{1}, E_{2} \geq 0$, we have that $\mathcal{H}(u)$ is semi-negative definite, and therefore, the result follows.

(v) There exist constants $a_{1}>0, a_{2}>0$, and $\beta>1$ such that the integrand $L(t, x, y, v, z, w)$ of the objective function (2.2) is bounded by

$$
L(t, x, y, v, z, w) \leq a_{1}-a_{2}\left(\left|u_{1}\right|^{2}+\left|u_{2}\right|^{2}\right)^{\beta / 2} .
$$

From (2.2), we have

$$
L(t, x, y, v, z, w)=x(t)+z(t)+w(t)-v(t)-\frac{E_{1}}{2} u_{1}^{2}(t)-\frac{E_{2}}{2} u_{2}^{2}(t) .
$$

By taking $E=\min \left\{E_{1}, E_{2}\right\}$ in (3.4), we find that

$$
L(t, x, y, v, z, w) \leq 3 M-\frac{E}{2}\left(u_{1}^{2}(t)+u_{2}^{2}(t)\right) .
$$

Hence, we can write

$$
L(t, x, y, v, z, w) \leq a_{1}-a_{2}\left(u_{1}^{2}(t)+u_{2}^{2}(t)\right)
$$

where $a_{1}=3 M>0, a_{2}=\frac{E}{2}>0$, and $M$ is the upper bound of the state solutions $x(t)$, $z(t), w(t)$. This implies that the inequality (3.3) holds true with $\beta=2>1$.

From the above statements (facts), we deduce the existence of the optimal controls $u_{1}^{*}$ and $u_{2}^{*}$. To obtain the expressions of $u_{1}^{*}$ and $u_{2}^{*}$, we use (3.1) with $H$ defined in (3.2). This gives that

$$
\begin{aligned}
& -E_{1} u_{1}+\frac{\beta_{1} v x}{1+\alpha \nu}\left(\lambda_{1}-\lambda_{2}\right)=0, \\
& -E_{2} u_{2}-n \lambda_{3} \delta y=0 .
\end{aligned}
$$


Hence, we find that

$$
\begin{aligned}
& u_{1}^{*}(t)= \begin{cases}0 & \text { if } u_{1} \leq 0, \\
\frac{\left(\lambda_{1}(t)-\lambda_{2}(t)\right) \beta_{1} v^{*}(t) x^{*}(t)}{E_{1}\left(1+\alpha v^{*}(t)\right)} & \text { if } 0<u_{1}<1, \quad \text { and } \\
1 & \text { if } u_{1} \geq 1,\end{cases} \\
& u_{2}^{*}(t)= \begin{cases}0 & \text { if } u_{2} \leq 0 \\
-\frac{n \delta \lambda_{3}(t) y^{*}(t)}{E_{2}} & \text { if } 0<u_{2}<1 \\
1 & \text { if } u_{2} \geq 1\end{cases}
\end{aligned}
$$

\section{Numerical simulation}

In this section, we investigate the optimal control numerically for studying the effectiveness of the drug on disease. At first, we replace the values of the parameters of Column 1, Column 2, Column 3, and Column 4 of Table 2 in model (2.1). Next, we choose the initial values from Table 3 and set $E_{1}=1, E_{2}=10$, and $t_{f}=10$. To numerically solve the optimal control problem (2.1) and (2.2), we use the Applied Modeling Programming Language AMPL [37]. We work with a grid of $N_{f}=1000$ grid points with nodes $t_{i}=i h, h=\frac{t_{f}}{N_{f}}$, $i=0,1, \ldots, N_{f}$ and use the Euler method. The proliferation of infected cells and viruses for the values of Column 1 of Table 2 are shown in Fig. 1(a)-(g). Figure 2(a)-(g) shows that for the values of Column 2 of Table 2, the amount of $u_{1}$ and $u_{2}$ affects the spread of disease. Figure 3(a)-(g) illustrates that for the values of Column 3 of Table 2, the effect of the drug on the proliferation of infected cells, viruses, cellular and humoral immunes.

In Fig. 4(a)-(b), the population of infected $C D_{4}^{+}$T-cells is represented in the presence of treatment control functions with an initial value of $y(0)=80$, which is initially reduced

\begin{tabular}{|c|c|c|c|c|c|c|}
\hline Parameters & Units & Column 1 & Column 2 & Column 3 & Column 4 & References \\
\hline$r$ & day $^{-1}$ & 2 & 2 & 2 & 2 & Assumed \\
\hline$m$ & & 15,000 & 100,000 & $5 \times 10^{4}$ & 300,000 & Assumed \\
\hline$\beta_{1}$ & ml.(virion.day $)^{-1}$ & $4.8 \times 10^{-7}$ & $4.8 \times 10^{-7}$ & $4.8 \times 10^{-7}$ & $4.8 \times 10^{-7}$ & [38] \\
\hline$\beta_{2}$ & $m l .(\text { virion.day })^{-1}$ & $4.7 \times 10^{-7}$ & $4.7 \times 10^{-7}$ & $4.7 \times 10^{-7}$ & $4.7 \times 10^{-7}$ & {$[38]$} \\
\hline$\alpha$ & cells $\mathrm{s}^{-1} \mathrm{ml}$ & 0.001 & 0.001 & 0.001 & 0.001 & [39-42] \\
\hline$\rho$ & day $^{-1}$ & 0.01 & 0.01 & 0.01 & 0.01 & [39-42] \\
\hline d & day $^{-1}$ & 0.02 & 0.02 & 0.02 & 0.02 & [39-42] \\
\hline$\delta$ & day $^{-1}$ & 0.5 & 0.5 & 0.5 & 0.5 & [39-42] \\
\hline$\rho_{1}$ & ml.(cells.day) $)^{-1}$ & 0.001 & 0.001 & 0.001 & 0.001 & {$[39-42]$} \\
\hline$n$ & ml.virion & 1200 & 1200 & 1200 & 1200 & [39-42] \\
\hline$\mu$ & $\operatorname{day}^{-1}$ & 3 & 3 & 3 & 3 & [39-42] \\
\hline$\rho_{2}$ & ml.(virion.day $)^{-1}$ & 0.5 & 0.001 & 0.001 & 0.001 & {$[43]$} \\
\hline$c_{1}$ & ml.(cells.day) $)^{-1}$ & 0.021 & 0.021 & 0.021 & 0.021 & Assumed \\
\hline$b_{1}$ & day $^{-1}$ & 0.2 & 0.2 & 0.2 & 0.2 & [39-42] \\
\hline$c_{2}$ & ml.(virion.day $)^{-1}$ & $10^{-11}$ & $10^{-11}$ & $10^{-4}$ & $10^{-4}$ & [43] \\
\hline$b_{2}$ & $d_{a y}{ }^{-1}$ & 0.1 & 0.1 & 0.01 & 0.1 & {$[43]$} \\
\hline
\end{tabular}

Table 2 The values of the parameters in the HIV mathematical model

Table 3 The initial values in HIV mathematical model

\begin{tabular}{lll}
\hline Variables & Initial values & Units \\
\hline$x(t)$ & $x(0)=200$ & $\mathrm{cell}^{\mathrm{m} l^{-1}}$ \\
$y(t)$ & $y(0)=80$ & $\mathrm{cell} . \mathrm{ml}^{-1}$ \\
$v(t)$ & $v(0)=12,000$ & $\mathrm{cell} . \mathrm{ml}^{-1}$ \\
$z(t)$ & $z(0)=50$ & $\mathrm{cell} . \mathrm{ml}^{-1}$ \\
$w(t)$ & $w(0)=100$ & $\mathrm{cell} . \mathrm{ml}^{-1}$ \\
\hline
\end{tabular}



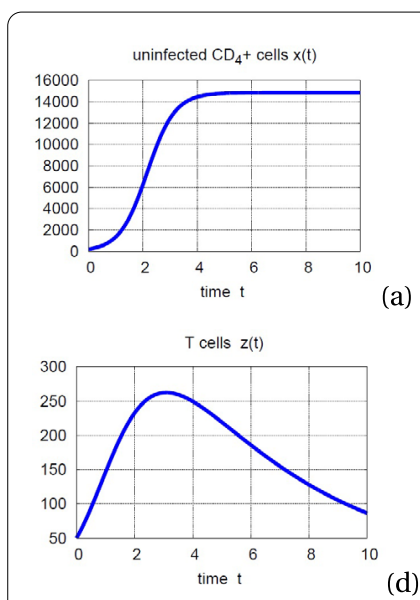

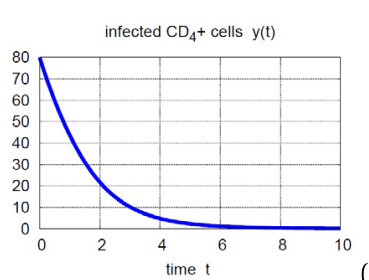

(b)

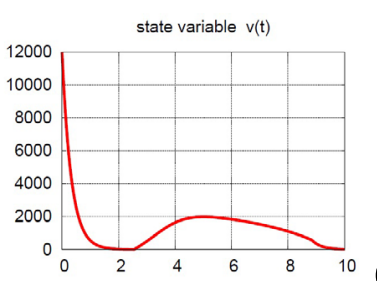

(c)
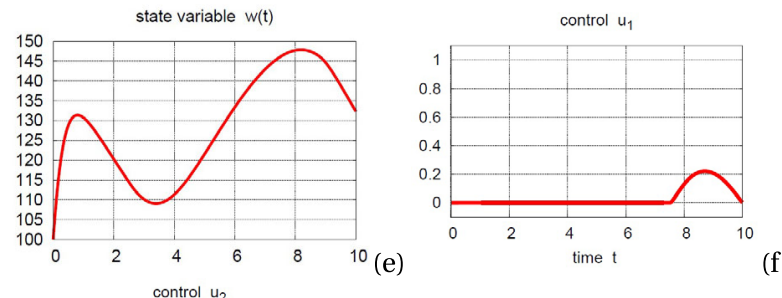

(f)

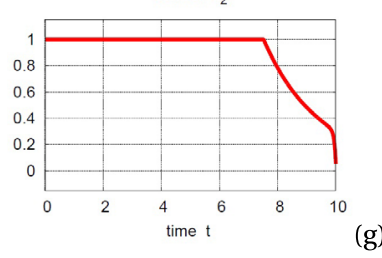

Figure 1 (a) Saturation level of uninfected $C D_{4}^{+}$T-cells with optimal control for Column 3 of Table 2 (b) Level of infected $C D_{4}^{+}$T-cells with optimal control for Column 3 of Table 2 (c) level of viral load with optimal control for Column 3 of Table 2 (d) level of T-cells with optimal control for Column 3 of Table 2 (e) level of B-cells with optimal control for Column 3 of Table 2 (f) Behavior of optimal control, $u_{1}^{*}$ as protease inhibitor for Column 3 of Table 2 (g) Behavior of optimal control, $u_{2}^{*}$ as reverse transcriptase inhibitor for Column 3 of Table 2
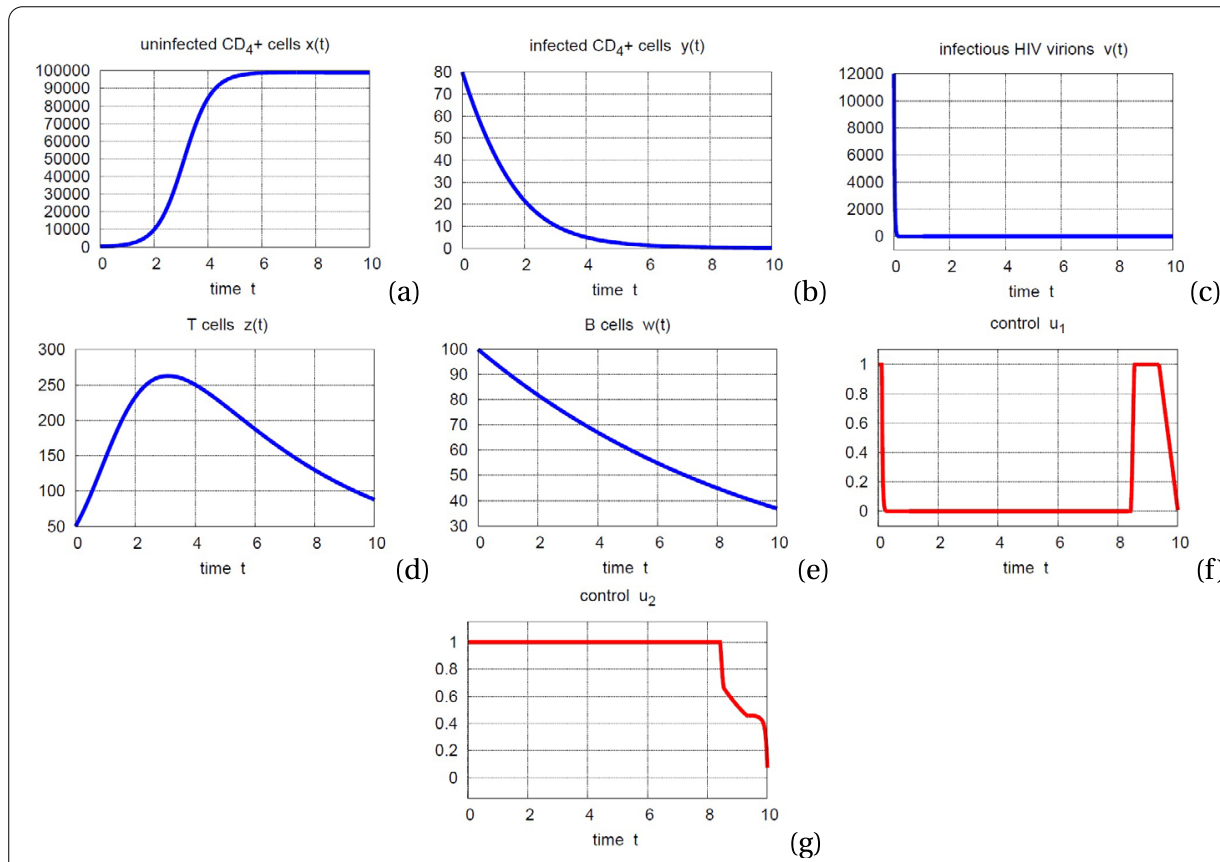

Figure 2 (a) Saturation level of uninfected $C D_{4}^{+}$T-cells with optimal control for Column 4 of Table 2 (b) Level of infected $C D_{4}^{+}$T-cells with optimal control for Column 4 of Table 2 (c) level of viral load with optimal control for Column 4 of Table 2 (d) level of T-cells with optimal control for Column 4 of Table 2 (e) level of B-cells with optimal control for Column 4 of Table 2 (f) Behavior of optimal control, $u_{1}^{*}$ as protease inhibitor for Column 4 of Table 2 (g) Behavior of optimal control, $u_{2}^{*}$ as reverse transcriptase inhibitor for Column 4 of Table 2 

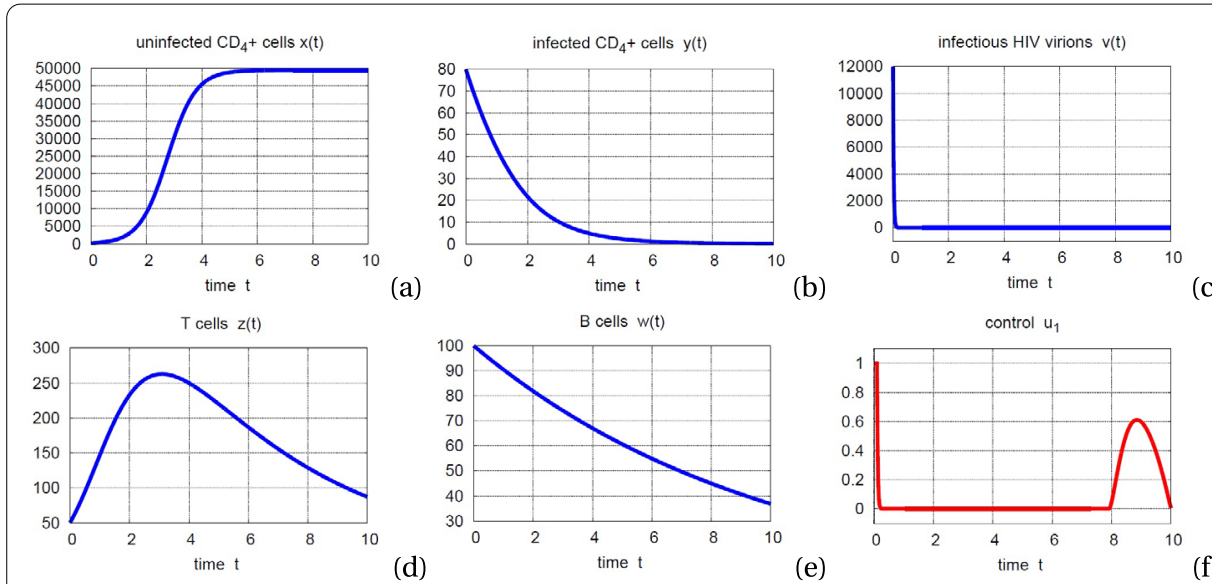

b)

(c)

(d)

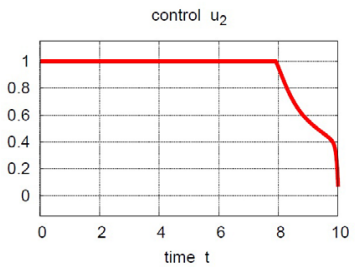

(e)

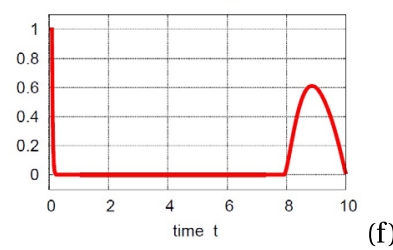

(g)

Figure 3 (a) Saturation level of uninfected $C D_{4}^{+}$T-cells with optimal control for Column 5 of Table 2 (b) Level of infected $C D_{4}^{+}$T-cells with optimal control for Column 5 of Table 2 (c) level of viral load with optimal control for Column 5 of Table 2 (d) level of T-cells with optimal control for Column 5 of Table 2 (e) level of B-cells with optimal control for Column 5 of Table 2 (f) Behavior of optimal control, $u_{1}^{*}$ as protease inhibitor for Column 5 of Table 2 (g) Behavior of optimal control, $u_{2}^{*}$ as reverse transcriptase inhibitor for Column 5 of Table 2
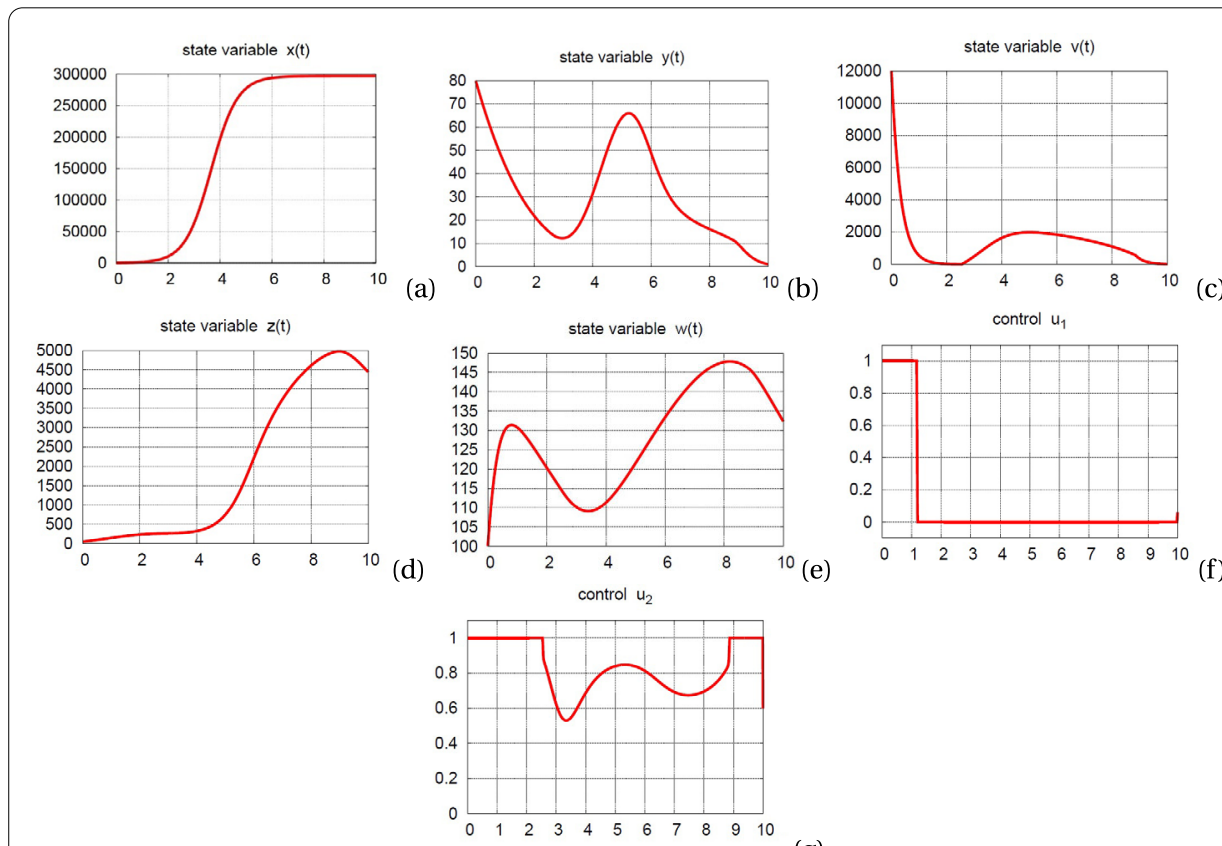

(g)

Figure 4 (a) Saturation level of uninfected $C D_{4}^{+}$T-cells with optimal control for Column 6 of Table 2 (b) Level of infected $C D_{4}^{+}$T-cells with optimal control for Column 6 of Table 2 (c) level of viral load with optimal control for Column 6 (d) level of T-cells with optimal control for Column 6 of Table 2 (e) level of B-cells with optimal control for Column 6 of Table 2 (f) Behavior of optimal control, $u_{1}^{*}$ as protease inhibitor for Column 6 (g) Behavior of optimal control, $u_{2}^{*}$ as reverse transcriptase inhibitor for Column 6 of Table 2 
by the initial proliferation of the population of uninfected $C D_{4}^{+} \mathrm{T}$-cells. By controlling the disease, the number of uninfected $C D_{4}^{+}$T-cells reaches the saturation level, and the population of infectious cells tends to zero. Figure 4(c) shows that the proliferation of the virus in the presence of treatment is gradually reduced to zero. Figure 4(d)-(e) depicts the level of proliferation of T-cells and B-cells in the presence of treatment, respectively. Finally, Fig. 4(f)-(g) represents the optimal controls $u_{1}^{*}$ and $u_{2}^{*}$ that simulate the reverse transcriptase and protease inhibitors for the values of Column 4 of Table 2.

\section{Conclusion}

In the present paper, we considered a five-dimensional model with the logistic function for replicating $C D_{4}^{+} \mathrm{T}$ cells, the saturation infection rate, and the treatment rate with two control functions to control the HIV-1 infection. There is no current definitive treatment for the HIV-1 infection. However, at the same time, several methods of treatment have been developed to control it. Because of the high costs of the treatment and side effects of drugs, we should minimize the dosages of drugs in the treatment. To this end, we introduce two controllers to identify the efficiency of reverse transcriptase and protease inhibitors. We used numerical values of the parameters to evaluate the model. Numerical methods used are based on optimal control to prevent the spread of infection and the production of new virus particles with minimal side effects through medication. The Pontryagin maximum principle was employed to provide the explicit formulations of the optimal controls. The optimal control process was numerically tested by replacing the values of Columns $1-4$ of Table 2 in the model (2.1). The numerical simulation shows that the virus load stops after treatment, and the spread of infected cells is reduced. The above results were obtained by using AMPL software. Numerical results of the model show that the concentration of infected cells increases before treatment and decreases after treatment. The results suggest that the optimal amount of drugs effectively better control AIDS and minimize the side effects of drugs.

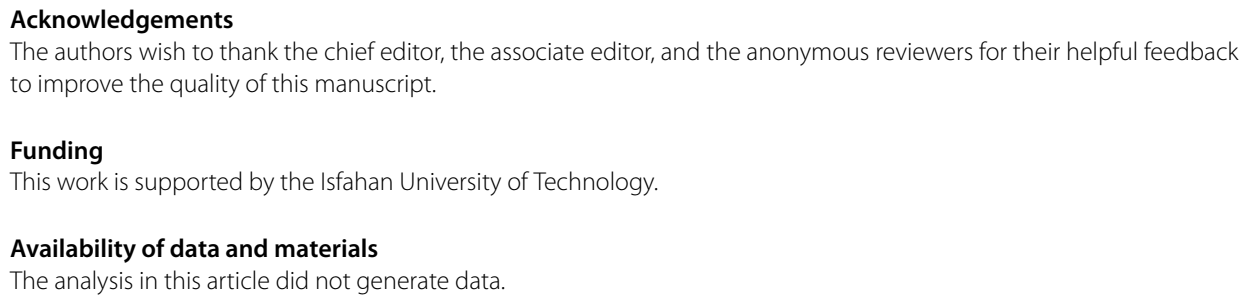

\section{Declarations}

Competing interests

The authors declare that they have no competing interests.

Authors' contributions

The authors were equally involved in writing this paper and read the final copy and agreed to the manuscript.

\section{Publisher's Note}

Springer Nature remains neutral with regard to jurisdictional claims in published maps and institutional affiliations. 


\section{References}

1. Nelson, P.W., Murray, J.D., Perelson, A.S.: A model of HIV-1 pathogenesis that includes an intracellular delay. Math. Biosci. 163(2), 201-215 (2000). https://doi.org/10.1016/S0025-5564(99)00055-3

2. Perelson, A.S., Nelson, P.W.: Mathematical analysis of HIV-1 dynamics in vivo. SIAM Rev. 41(1), 3-44 (1999). https://doi.org/10.1137/S0036144598335107

3. Ali, N., Zaman, G., Algahtani, O.: Stability analysis of HIV-1 model with multiple delays. Adv. Differ. Equ. 2016(1), 1 (2016). https://doi.org/10.1186/s13662-016-0808-4

4. Ali, N., Zaman, G., Alqahtani, A.M., Alshomrani, A.S.: The effects of time lag and cure rate on the global dynamics of HIV-1 model. BioMed Res. Int. 2017, Article ID 8094947 (2017). https://doi.org/10.1155/2017/8094947.

5. Essunger, P., Perelson, A.S.: Modeling HIV infection of $C D_{4}^{+}$T-cell subpopulations. J. Theor. Biol. 170(4), 367-391 (1994). https://doi.org/10.1006/jtbi.1994.1199

6. Nowak, M.A., Bangham, C.R.: Population dynamics of immune responses to persistent viruses. Science 272(5258), 74-79 (1996). https://doi.org/10.1126/science.272.5258.74

7. Kirschner, D.E., Webb, G.F.: A mathematical model of combined drug therapy of HIV infection. J. Theor. Med. 1(1), 25-34 (1997)

8. Wodarz, D., Hamer, D.H.: Infection dynamics in HIV-specific CD $C D_{4}^{+} \mathrm{T}$ cells: does a $C D_{4}^{+} \mathrm{T}$-cell boost benefit the host or the virus. Math. Biosci. 209(1), 14-29 (2007). https://doi.org/10.1016/j.mbs.2007.01.007

9. Martin, N., Sattentau, Q.: Cell-to-cell HIV-1 spread and its implications for immune evasion. Curr. Opin. HIV AIDS 4(2), 143-149 (2009). https://doi.org/10.1097/COH.0b013e328322f94a

10. Huang, G., Takeuchi, Y., Ma, W.: Lyapunov functionals for delay differential equations model of viral infections. SIAM J. Appl. Math. 70(7), 2693-2708 (2010). https://doi.org/10.1137/090780821

11. Sigal, A., Kim, J.T., Balazs, A.B., Dekel, E., Mayo, A., Milo, R., Baltimore, D.: Cell-to-cell spread of HIV permits ongoing replication despite antiretroviral therapy. Nature 477(7362), 95-98 (2011). https://doi.org/10.1038/nature10347

12. Yan, Y., Wang, W.: Global stability of a five-dimensional model with immune responses and delay. Discrete Contin. Dyn. Syst., Ser. B 17(1), 401-416 (2012). https://doi.org/10.3934/dcdsb.2012.17.401

13. Wang, Y., Zhou, Y., Brauer, F., Heffernan, J.M.: Viral dynamics model with CTL immune response incorporating antiretroviral therapy. J. Math. Biol. 67(4), 901-934 (2013). https://doi.org/10.1007/s00285-012-0580-3

14. Fouts, T.R., Bagley, K., Prado, I.J., Bobb, K.L., Schwartz, J.A., Xu, R., Gallo, R.C.: The balance of cellular and humoral immunity determines the level of protection by HIV vaccines in rhesus macaque models of HIV infection. Proc. Natl. Acad. Sci. 112(9), E992-E999 (2015). https://doi.org/10.1073/pnas.1423669112

15. Kamboj, D., Sharma, M.D.: Effects of combined drug therapy on HIV-1 infection dynamics. Int. J. Biomath. 9(05), 1650065 (2016). https://doi.org/10.1142/S1793524516500650

16. Ełaiw, A.M., Raezah, A.A., Hattaf, K.: Stability of HIV-1 infection with saturated virus-target and infected-target incidences and CTL immune response. Int. J. Biomath. 10(05), 1750070 (2017). https://doi.org/10.1142/S179352451750070X

17. Lin, J., Xu, R., Tian, X.: Threshold dynamics of an HIV-1 model with both viral and cellular infections, cell-mediated, and humoral immune responses. Math. Biosci. Eng. 16(1), 292-319 (2018) https://www.aimspress.com/fileOther/PDF/MBE/mbe-16-01-015.pdf

18. Zhou, $X .$, Song, $X$. Shi, $X .:$ A differential equation model of HIV infection of $C D_{4}^{+}$T-cells with cure rate. J. Math. Anal. Appl. 342(2), 1342-1355 (2008). https://doi.org/10.1016/j.jmaa.2008.01.008

19. Zhou, X., Song, X., Shi, X.: Analysis of stability and Hopf bifurcation for an HIV infection model with time delay. Appl. Math. Comput. 199(1), 23-38 (2008). https://doi.org/10.1016/j.amc.2007.09.030

20. Hattaf, K., Yousfi, N.: Dynamics of HIV infection model with therapy and cure rate. Int. J. Tomogr. Stat. 16(11), 74-80 (2011) http://www.ceser.in/ceserp/index.php/ijts/article/view/218

21. Perelson, A.S., Nelson, P.W.: Mathematical models of HIV dynamics in vivo. SIAM Rev. 41(1), 3-44 (1999). https://doi.org/10.1137/S0036144598335107

22. Mbogo, W.R., Luboobi, L.S., Odhiambo, J.W.: Stochastic model for in-host HIV dynamics with therapeutic intervention Int. Sch. Res. Not. Biomath. 2013, Article ID 103708 (2013). https://downloads.hindawi.com/archive/2013/103708.pdf

23. Ogunlaran, O.M., Oukouomi Noutchie, S.C.: Mathematical model for an effective management of HIV infection. BioMed Res. Int. 2016, Article ID 4217548 (2016). https://doi.org/10.1155/2016/4217548

24. Nampala, H., Luboobi, L.S., Mugisha, J.Y., Obua, C.: Mathematical modeling of liver enzyme elevation in HIV mono-infection. Math. Biosci. 242(1), 77-85 (2013). https://doi.org/10.1016/j.mbs.2012.12.005

25. Karrakchou, J., Rachik, M., Gourari, S.: Optimal control and infectiology, application to an HIV/AIDS model. Appl. Math. Comput. 177(2), 807-818 (2006). https://doi.org/10.1016/j.amc.2005.11.092

26. Srivastava, P.K., Banerjee, M., Chandra, P.: Modeling the drug therapy for HIV infection. J. Biol. Syst. 17(02), 213-223 (2009). https://doi.org/10.1142/S0218339009002764

27. Bakare, E.A., Nwagwo, A., Danso-Addo, E.: Optimal control analysis of an SIR epidemic model with constant recruitment. Int. J. Appl. Math. Res. 3(3), 273-285 (2014). https://doi.org/10.14419/ijamr.v3i3.2872

28. Ali, N., Zaman, G., Alshomrani, A.S.: Optimal control strategy of HIV-1 epidemic model for recombinant virus. Cogent Math. 4(1), 1293468 (2017). https://doi.org/10.1080/23311835.2017.1293468

29. Hattaf, K., Yousfi, N.: Two optimal treatments of HIV infection model. World J. Model. Simul. 8(1), 27-36 (2012)

30. Pontryagin, L.S.: Mathematical Theory of Optimal Processes. CRC Press, Boca Raton (1987)

31. Kaminski, R., Bella, R., Yin, C., Otte, J., Ferrante, P., Gendelman, H.E., Khalili, K.: Excision of HIV-1 DNA by gene editing: a proof-of-concept in vivo study. Gene Ther. 23(8), 690-695 (2016). https://doi.org/10.1038/gt.2016.41

32. Smith, H.L., De Leenheer, P.: Virus dynamics: a global analysis. SIAM J. Appl. Math. 63(4), 1313-1327 (2003) https://www.jstor.org/stable/4095962

33. Perelson, A.S.: Modeling the interaction of the immune system with HIV. In: Mathematical and Statistical Approaches to AIDS Epidemiology, vol. 83, pp. 350-370 (1989). https://doi.org/10.1007/978-3-642-93454-4-17

34. Xu, R.: Global stability of an HIV-1 infection model with saturation infection and intracellular delay. J. Math. Anal. Appl. 375(1), 75-81 (2011). https://doi.org/10.1016/j.jmaa.2010.08.055

35. Neilan, R.L.M., Schaefer, E., Gaff, H., Fister, K.R., Lenhart, S.: Modeling optimal intervention strategies for cholera. Bull. Math. Biol. 72(8), 2004-2018 (2010). https://doi.org/10.1007/s11538-010-9521-8 
36. Fleming, W.H., Rishel, R.W.: Deterministic and Stochastic Optimal Control. Springer, Berlin (2012)

37. Fourer, R., Gay, D.M., Kernighan, B.W.: AMPL, a modeling language for mathematical programming. Manag. Sci. 36(5), 519-554 (1990). https://doi.org/10.1287/mnsc.36.5.519

38. Wang, J., Guo, M., Liu, X., Zhao, Z.: Threshold dynamics of HIV-1 virus model with the cell-to-cell transmission, cell-mediated immune responses and distributed delay. Appl. Math. Comput. 291, 149-161 (2016). https://doi.org/10.1016/j.amc.2016.06.032

39. Tabit, Y., Hattaf, K., Yousfi, N.: Dynamics of an HIV pathogenesis model with CTL immune response and two saturated rates. World J. Model. Simul. 10(3), 215-223 (2014)

40. Tabit, Y., Meskaf, A., Allali, K.: Mathematical analysis of HIV model with two saturated rates, CTL and antibody responses. World J. Model. Simul. 12(2), 137-146 (2016)

41. Fister, K.R., Lenhart, S., McNally, J.S.: Optimizing chemotherapy in an HIV model. J. Differ. Equ. 32(1998), 1-12 (1998) https://digital.library.txstate.edu/handle/10877/7929

42. Butler, S., Kirschner, D., Lenhart, S.: Optimal control of chemotherapy affecting the infectivity of HIV. In: Advances in Mathematical Population Dynamics: Molecules, Cells, Man, pp. 104-120. World Scientific, Singapore (1997)

43. Wang, X., Wang, W.: An HIV infection model based on a vectored immunoprophylaxis experiment. J. Theor. Biol. 313 , 127-135 (2012). https://doi.org/10.1016/j.jtbi.2012.08.023

\section{Submit your manuscript to a SpringerOpen ${ }^{\circ}$ journal and benefit from:}

- Convenient online submission

- Rigorous peer review

- Open access: articles freely available online

- High visibility within the field

- Retaining the copyright to your article

Submit your next manuscript at $\mathbf{s p r i n g e r o p e n . c o m ~}$ 